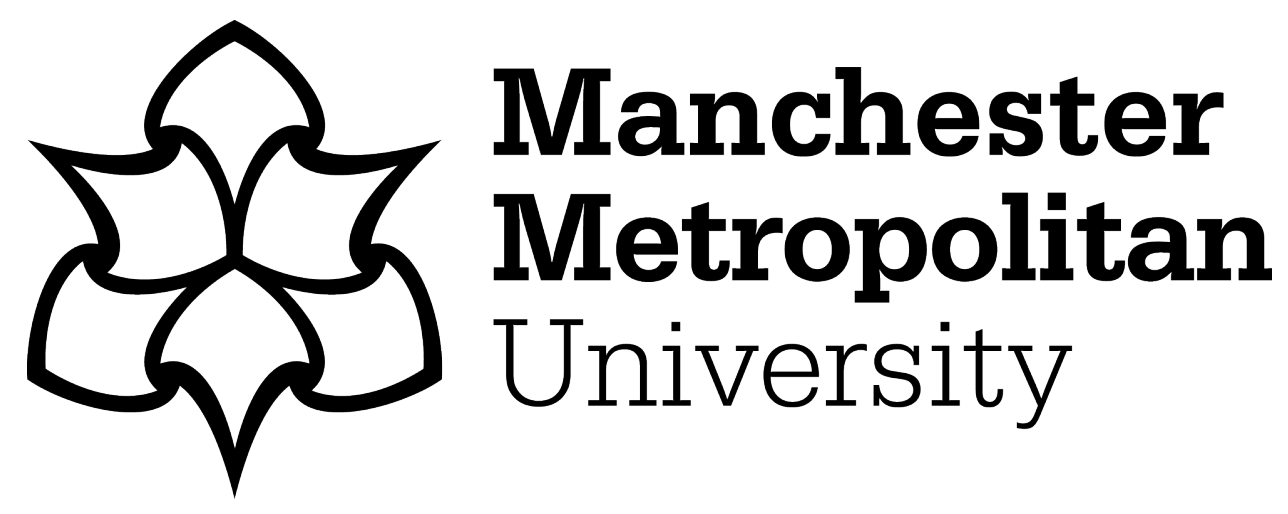

Meyer, R and Vasey, H (2020) Immigration, Social Networks, and the Emergence of Ethnic Segmentation in a Low-Skill Labor Market. Social Science Computer Review, 38 (4). pp. 387-404. ISSN 0894-4393

Downloaded from: https://e-space.mmu.ac.uk/622122/

Version: Accepted Version

Publisher: SAGE Publications

DOI: https://doi.org/10.1177/0894439318815636

Please cite the published version 


\title{
Immigration, social networks and the emergence of ethnic segmentation in a low-skill labour market
}

\author{
Ruth Meyer, Manchester Metropolitan University
}

Huw Vasey, University of Manchester

\section{Abstract:}

Post-war migration to 'western' countries has gone hand-in-hand with the development of ethnically segmented labour markets, particularly in low-skill roles where entry requirements are minimal. Whilst numerous theories have been forwarded as to why such situations occur, it has remained difficult to empirically test the relative impact of the many interacting processes that produce segmentation in the labour market. In this paper, we investigate the processes of ethnic segmentation in low-skilled labour markets, where referral hiring is the norm, with particular reference to the role of ethnically homogenous social networks and forms of discrimination. We employ an agent-based modelling (ABM) approach, adapting key elements from Waldinger \& Lichter's (2003) widely cited networked explanation of ethnic labour market segmentation. This ABM approach allows us to provide a different lens on theories of ethnic labour market segmentation, investigating the relative impacts of different causal processes that are difficult to investigate in this way using other social science $\sim 1 \sim$ 
approaches. The overall results from our model indicate that ethnically homogenous social networks have the effect of increasing the level of ethnic segmentation within a referral-based labour market, but that these networks also help immigrant populations grow and protect them from the negative impacts of employer discrimination. Furthermore, these networks have a greater impact on labour market segmentation than discrimination alone. In conclusion, this sociologically-informed ABM provides important insights into the manner and extent in which changes in social conditions may affect population-level phenomena.

\section{Keywords:}

Agent-based modelling; complexity; immigration; labour market segmentation; social networks 
Immigration, social networks and the emergence of segmentation

\section{Introduction}

Researchers have long observed that some level of ethnic segmentation occurs amongst low-skill roles in labour markets where large numbers of migrants are received (see, e.g. Massey et al., 1993; Sassen, 1996; Wills et al., 2010). However, whilst this is occasionally due to a specific and sustained attempt by the receiving country to attract and limit immigrant workers to certain roles (Stalker, 2000), it is more commonly a phenomenon that appears to have no bureaucratic roots. In the language of complexity studies, it is emergent - that is, it arises from a concatenation of loosely related events and processes which, moreover, could not have been predicted from initial conditions alone.

In this article we present findings based on an agent-based model (ABM) developed from the network-based, immigration-driven description of ethnic labour-market segmentation given in Waldinger \& Lichter's (2003) highly cited study, How the Other Half Works. Whilst the notion that social networks influence the development of ethnic segmentation in low-skilled jobs has been widely embraced amongst migration scholars (see, e.g. Boyd \& Nowak, 2012), it has proved difficult to analyse how this occurs in varying locations, and the strength of this causal process in comparison to other factors shown to influence the development of ethnic segmentation, such as discrimination by employers. Employing a sociologically informed ABM allows us the opportunity to develop an in vitro model (Edmonds, 2013) to test the mechanisms and relative strength of social networks as a casual factor behind segmentation in low-skilled labour markets. 
Whilst many academics have forwarded empirically-based theories as to why ethnic labour market segmentation may arise, the interconnected and overlapping nature of the non-linear causal processes involved makes it extremely difficult to begin to uncover the extent to which such proposed theories can be usefully extended to help us understand similar situations in different times, spaces and places.

Approaches that have attempted to explain labour market segmentation by trying to 'reverse engineer' the processes involved, such as those using regression statistical modelling techniques, are restricted in their explanatory scope due to their linear nature. Whilst such techniques can be extremely useful to the migration scholar, particularly when explaining the strength of relationships between independent variables (such as ethnicity, nationality, age, level of education or gender) and a dependent outcome (for example, wage level, or the 'segmentedness' of sectors of employment), they are only able to theorise as to why such a relationship may have developed and how local conditions may have influenced the development of such an association. In essence, they can provide a broad retrospective snapshot of the relationships between variables, but struggle to explain any emergent causation (see, e.g. Sorensen, 1998).

Equally, in-depth qualitative and ethnographic studies of labour market segmentation have provided illuminating examples of how and why such processes occurred under the specific conditions under investigation, yet the very depth they provide limits the potential breadth of any explanatory power they may produce. In essence, they provide a very detailed picture of the functioning of the processes involved in labour market 
Immigration, social networks and the emergence of segmentation

segmentation within a very constrained time-space, yet struggle to generalise those findings to similar processes in other times and spaces.

The use of agent-based models (ABMs), however, represents a shift not only from solely investigating variables and factors that might impinge upon a situation, but also from exclusively concentrating on a single in-depth case study. Instead, a consideration of socially-embedded individuals is produced, which allows for an experimental analysis of the interaction between the processes that act upon those agents. In this way, it combines elements of both quantitative and qualitative approaches to social phenomena.

Furthermore, ABMs are particularly well suited to the study of complex social phenomena (Gilbert \& Troitzsch, 2005). Complex systems are neither inherently orderly nor intrinsically disorderly but switch between both without solely being explained by either. Indeed, many social systems, including international migration (Papastergiadis, 2000) appear to fit into such a typology in that they exhibit key qualitative and phenomenological elements of a complex system (see, e.g. Geyer \& Rihani, 2010; Mol \& Law, 2002; Sawyer, 2005).

Agent-based modelling is a simulation approach in which discrete computer generated 'agents' are imbued with limited autonomy, a capability to adapt or react to the environment, and are involved in local interactions. In this way, 'agents' in ABMs have agency in a way that is very familiar to migration scholars. Whilst this artificial agency is bounded by the simple rules of engagement programmed into the model, the interplay of discrete agents following their own sets of rules can produce non-linear outcomes on $\sim 5 \sim$ 
a 'population' level. In this way, ABMs allow us to explore the same processes as existing sociological methods in a novel way. Furthermore, this novelty allows us to investigate non-deterministic social systems 'from the bottom up' in a way which is simply not possible using existing methods. For Edmund Chattoe-Brown (2013) such an approach is highly useful for social science because it presents another 'lens' on society, reframing existing sociological questions and allowing for a very different conceptualisation of causation. Whilst such an approach should not be considered a replacement for existing methods, it does provide both a useful addition in itself and a way to combine existing data (quantitative or qualitative) in a novel manner.

\section{$2 \quad$ Related Work}

Whilst there have been no previous attempts to model the segmentation of migrant labour markets in the ABM tradition, there have been attempts to look at the effects of social networks and homophily in the development of workplace inequality and segregation. Gemkow \& Neugart (2011), for example, have explored the role of referral hiring and endogenous social networks in the development of labour inequality - both of which are central to Waldinger \& Lichter's conceptualisation of ethnic labour market segmentation. For Gemkow \& Neugart, workers cultivate costly networks of friendships in order to insure themselves against long bouts of unemployment. These networks act as a protection in their model because employers prefer to hire via referrals garnered from their existing workforce. Meanwhile, friendships cost a set amount to maintain over a certain time-period; therefore, an agent is only likely to retain enough social contacts to insure them against prolonged unemployment. Their key finding is that the combination of endogenous social networks and referral hiring tended to produce $\sim 6 \sim$ 
Immigration, social networks and the emergence of segmentation

labour market inequality in terms of the individual incidence of unemployment when the labour market was less volatile, but less inequality and smaller social networks in more volatile markets. However, we must remember that, in this model, maintaining costly social ties is an entirely rational economic choice.

Calvo-Armengol \& Jackson (2004), meanwhile, have illustrated how social networks positively correlate with employment patterns across time and between groups, but that when information about job vacancies spread through such networks, unemployed agents find themselves increasingly 'locked out' of employment as their term out of work increases. Furthermore, in a later article, the same authors (2007) observed that initial differences in wage levels and employment status are maintained over time for groups with identical social network structures.

Krauth (2004) shows that, under conditions of referral hiring, an agent can increase their chance of getting hired by enlarging their social networks, particularly with ties to those already in work. Additionally, the work of Tassier \& Menczer (2008) has revealed that, whilst random social networks increase one's likelihood of hearing about a vacancy, that information is also likely to be widely known. Where social networks are non-random, job information is shared with a smaller number of agents and employment rates for that social network increase.

Abdou \& Gilbert (2009) have modelled the relationship between social and workplace segmentation with reference to Egypt, illustrating how high levels of referral hiring lead to an increase in both forms of segmentation, particularly where there is a smaller minority population, or in smaller firms. Crucially, however, they recognise that, in $\sim 7 \sim$ 
terms of overall employment rates, 'increasing levels of referral hiring could be beneficial for minority groups when the population is highly segregated and harmful otherwise' (2009: 19).

Whilst these models deal with simplified scenarios compared to the rich data sources often utilised by sociologists, they do illustrate some important emergent properties of networked labour markets. Firstly, the structure of social networks matters for both an individual agent's chance of getting a job, but also for the development of populationlevel phenomena, such as segmentation. Secondly, the relative size of a minority population, the size of firms involved and their propensity to favour referral hiring techniques all contribute to the extent and type of segmentation, which occur. Indeed, for those familiar with Waldinger and Lichter's work on ethnically segmented labour markets in 1990's Los Angeles, these phenomena are recognisable; they stress the importance of homophilic social networks to getting a job, but also note that differences in employers' preferences for referral hiring affects the make-up of a workforce (2003: 97).

This kind of ethnic segmentation, complete with referral hiring and self-regulation, has been widely reported in more recent studies investigating 'migrant labour markets' (Bauder, 2006; McDowell et al., 2009; Wills et al., 2010). Considering the consistency of Waldinger \& Lichter's work with both findings presented in previous ABMs of networked job markets and qualitative studies of migrant divisions of labour, it seems clear that producing an agent-based model of Waldinger \& Lichter's notion of the socially-networked organisation of migrant labour holds the potential to reveal a number of interesting insights into the functioning of this complex system. Furthermore, $\sim 8 \sim$ 
Immigration, social networks and the emergence of segmentation

the in vitro nature of an $\mathrm{ABM}$ allows to conduct experiments which are not possible using other sociological methods.

\section{Model framework - specifying How the Other Half Works}

In their seminal study of immigration and the social organisation of labour in Los Angeles, Waldinger \& Lichter not only provide a neatly defined area of study - LA in the 1990 's - but also supply some highly testable scenarios that are both interesting from a sociological perspective and lend themselves well to an agent-based modelling approach. In this paper, we ask the questions, 'Can social networks alone drive ethnic segmentation in a low-skill labour market?', and, 'How do social networks interact with discriminatory practices by employers in a low-skill labour market?'. These are important questions in the sociology of immigration and work, because whilst we are well aware such segmentation happens (often rapidly), there is less clarity about the processes that drive it. Is it simply an effect of the functioning of social networks, or do we need to take into account other socially embedded processes, particularly discrimination and job queuing (Wills at al., 2010)? Indeed, even if we agree that many of the factors have an impact, the relative extent of the effect of social networks is difficult to gauge by other sociological methods; perhaps an ABM could cast light on this?

Waldinger \& Lichter's conceptualisation of how social networks impact on labour market segmentation (2003: 83-99) is based on two assumptions: (i) 'Most job-seekers activate their social connections to find jobs' and (ii) 'Employers use ties linking the workers whom they know to the new people they may like to hire'. 
Waldinger \& Lichter suggest four elements to consider here, according to their interpretation of the current sociological literature:

1) Networks provide information - 'telling job seekers about opportunities and informing employers about the characteristics of applicants'.

2) Networks are instruments of influence - 'allowing job seekers to put themselves on the inside track by proxy'.

3) Networks can be used to enforce obligations - 'so that the employer is assured that the favors he or she does for the job-seeker and his or her accomplices will be repaid'.

4) Networks can cement implicit contracts - because networks are carriers of information and obligation, they can be used to impose the 'rights and responsibilities of each party of the employment exchange.' Furthermore, '[t]o the extent that a group of workers feels bound by these understandings, the employer can count on its exercise of social control to keep recalcitrant fellows in line' (ibid).

In the model described in this paper, we only model the flow of information and influence through networks. Obligations and implicit contracts, though important to a sociological understanding of referral-based network recruitment, are based on implicit systems, which were not evidenced enough in the study for us to convert into explicitly modelled functions. It can be argued, however, that giving employers a preference for referral hiring over hiring applicants who just 'walked in' off the streets is an implicit representation of the obligation aspect.

$\sim 10 \sim$ 
Immigration, social networks and the emergence of segmentation

The above conceptualisation suggests two types of agent to be modelled:

1) Workers - they look for jobs and are enmeshed in social networks. They can pass information about vacant jobs through these networks, and also get a boost to their likelihood of getting a job they have heard about through such a connection.

2) Employers - they give out jobs and use the social networks of their existing workforce for recruitment. They have a preference for recruiting workers in the same social networks as their existing workforce.

Additionally, we need to represent:

Social networks - these connect groups of workers. They provide information about available jobs at the employers of social network group members. They also provide an advantage to getting a job where other network members are already employed in an organisation (influence).

\section{$4 \quad$ Model description}

\subsection{Overview}

The model adapts key elements from the case study of the low-skill labour market in Los Angeles described by Waldinger \& Lichter (2003). It is initialised in a scenario similar to the early 1960s in LA: low-skilled jobs are arranged in a variety of firms of six different industries (printing, furniture manufacturing, restaurants, hotels, department stores, hospitals). Most of these jobs are initially filled by a native majority population ('Whites') who slowly vacate the jobs as they retire and rarely compete for newly $\sim 11 \sim$ 
vacated jobs - equivalent to a white working class moving up the labour market hierarchy in the post-war era (ibid: 9). The rest of the filled jobs are initially taken by a 'native' minority group equivalent to US-born African-Americans ('Blacks'). A small number of 'pioneer' immigrants of two different ethnicities ('Latino' and 'Asian') are also present looking for work.

Employers collect 'job applications' and employ their chosen agent. They have a preference for those 'recommended' by their employees - i.e. those with pre-existing network ties to these employees. Newly employed agents may then form new links with co-ethnics with whom they work - though agents do not form cross-ethnic links in this model, mimicking linguistic barriers.

Since the model focuses on the labour market, it only considers a population of working age agents (18-64). Agents who reach 65 retire and leave the model. New agents enter the model at age 18 according to the birth rate of their respective ethnicity or - in the case of the two non-native ethnic groups - by immigration. Other demographic processes are not within the scope of the model. Family or neighbourhood ties are modelled by new agents trying to find a position close to other agents of their own ethnicity in the model world, and then forming links with them.

Another reason for agents to leave the modelled labour market is 'discouragement' (see, e.g. Herzog, Schlottmann \& Boehm, 1993). This will occur if they fail to get a job for a set period of time (1 year in the experiments described in this paper). It is modelled as a probability of leaving (set to $10 \%$ ), which is tested every time-step once the crucial time 
Immigration, social networks and the emergence of segmentation

period for an agent has been reached. Both 'native' and 'immigrant' agents can become discouraged.

Our aim in designing the model has been to incorporate as much available data from the case study as possible, while still keeping the model as simple as possible. Due to the latter design concept, the labour market is restricted to low-skill jobs with no entry requirements; therefore skills of workers are not represented in this model version. To an employer, applicants for a vacant job are indistinguishable but for their ethnicity and number of links they have to the existing workforce. Similarly, workers do not have preferences for a particular job at a particular firm; to them all jobs are the same and they will apply to any firm one of their employed friends will tell them about.

The data we could derive from Waldinger and Lichter's study is used to initialise both the labour market and the initial population of worker agents (see section 4.4). It has also been applied in calibrating the model so that its overall population dynamics correlate with the trajectories of the numbers of unskilled workers per ethnic group as reported in the study. This was necessary as no data regarding actual, historical immigration rates (i.e. including illegal immigration to the case study area) was available.

\subsection{Model entities}

The model is implemented in NetLogo (Wilensky, 1999). It distinguishes two types of agents, realised as breeds in NetLogo:

1. Workers: Worker agents represent individual people seeking employment in the low-skill labour market. They are characterized by their age (18-65), sex 
(male/female) and ethnicity (an integer between 0 and number of ethnicities - 1 , which in this case is assigned as 0 -White, 1-Black, 2-Latino and 3-Asian). Each worker agent also keeps tabs on the job they have (attribute job, set to 1 if unemployed), how long they have been unemployed for (ticksunemployed) and a list of current vacancies (job-offers) they know of via their friends.

2. Employers: Each employer agent represents a firm in the model. Firms are characterized by their type (one of six, attribute industry-index), their size (number of low-skill jobs, num-jobs), and their yearly turnover rate (annualchurn-rate). These are all taken from the available case study data (see section 4.4). Employer agents keep tabs on which of their jobs are vacant or taken (vacant-jobs / filled-jobs), who is currently applying for a job (applicants / walk-ins - the former have heard about a vacancy via their friendship network, the latter have not), and recommendations of their existing employees for particular applicants (referrals). For ease of producing model output measures, employers also keep track of how many workers of each ethnicity they currently employ (ethnicity-counts).

In addition to these type-specific attributes, each agent has a unique id (attribute who, automati-cally assigned in NetLogo) and a location (given as the $x-y$ coordinates of the grid cell they in-habit: xcor, ycor).

Both friendship and work relations are expressed as network links (realised as different link breeds in NetLogo). When a worker is hired a new work relation link between the 
Immigration, social networks and the emergence of segmentation

employer and the worker is formed; this is dropped again when the worker leaves the firm due to retirement or being fired. Friendship links are established between workers of the same ethnicity throughout the simulation; they are deleted whenever a worker agent leaves the model due to retirement or discouragement.

The model world consists of a 2D grid of cells with "wrapped-around" borders. The cells serve as locations for agents (employers or workers). Space in the model is abstract insofar as it does not represent any geographical features of the modelled area (Los Angeles); thus, a cell does not represent any particular real-world area. The size of the model world (number of cells) is adapted at the beginning of a simulation to easily fit the initial number of agents.

The size of the model in terms of number of agents is driven by the labour market, which is specified by the number and type of firms and the number of jobs they each provide. These remain fixed throughout the simulation, i.e. firms do not expand or shrink and no new firms will enter the model. The number of firms can be set via the model parameter num-employers, whereas their attributes (type, number of jobs, annual churn rate) are determined from the case study. The initial number of worker agents is calculated from the total number of jobs, the unemployment rate (model parameter initial-unemployment-rate), the proportion of vacant jobs (model parameter initialvacancy-proportion) and the ethnicity proportions of the worker population (model parameter eth-proportions). 


\subsection{Process overview and scheduling}

With the default setting, one time step represents a week. This can be changed by setting the model parameter ticks-per-year to a value different than 52. All simulations reported in this paper were run for 30 years (1560 ticks).

At the beginning of each tick, internal variables are updated. This includes the age of workers (if the tick marks the beginning of a new year), which in turn may cause some workers to retire and leave the model. The main model processes are then carried out in the following order (with sets of agents always activated in random order):

1. Advertise vacancies: Employers 'advertise' any vacancies by notifying their employees.

2. Spread the word: Employed workers tell their unemployed friends about any vacancies they know of. They also recommend them to their employer, i.e. send a "referral" for each unemployed friend.

3. Apply for job: Unemployed workers apply for jobs. If they know of any vacancies, this means they send applications to the employers in question. Otherwise, they walk in at the nearest employer with vacancies to ask for a job. The model assumes here that a time step of a week is enough for any unemployed worker without ties to the employed workforce to complete such a search successfully (if there are any vacancies).

4. Screen applications: Employers pick a new employee for each of their vacancies (there can be more than one at a time) according to the specified recruitment strategy (model parameter e-selection-method). In the standard 
Immigration, social networks and the emergence of segmentation

model described here, this will be 'normal' referral hiring, i.e. the applicant with the most recommendations from existing employees will be chosen, regardless of their ethnicity ${ }^{1}$. With 'internal' bias, employers strive to keep the ethnic composition of their workforce as it is, whereas with 'external' bias, they strive to match their workforce to the ethnic composition of the population (see section 5.2).

5. Leave discouraged: Unemployed workers update their unemployment time (attribute ticks-unemployed). If they have reached the threshold of time they are willing to wait until they get a job (model parameter ticks-discouraged), they may leave the model with a specified probability (model parameter prob-discouraged).

6. Job churn: Employers check if some staff turnover is happening in this tick, determined by their industry's annual turnover rate (attribute annual-churnrate).

At the end of each tick, demographic processes occur. These are immigration for the non-native ethnicities (Latinos, Asians) and 'births' of 18-year-olds for all ethnicities. In addition, worker agents may grow their social network. All model processes are described in more detail in the model documentation available online with the model code (Meyer, 2018).

\subsection{Initialisation}

The model is initialised using the available data from the case study (Waldinger \& Lichter, 2003: 235-252). The characteristics of the firms forming the labour market are $\sim 17 \sim$ 
determined by distributions derived from tables A2-A9, with the values shown in Table 1.

[Insert Table 1 about here]

From this, the number of firms, and their initial vacancy proportion (model parameters num-employers and initial-vacancy-proportion) the modelled labour market is constructed. Locations of firms are assigned randomly. To be able to compare different simulation runs for the same labour market, a particular setup may be read in from a text file.

The model starts from a state where only native workers are employed whereas all immigrants already present are unemployed. The total number of agents and their ethnic composition can be calculated from the number of initially filled and vacant jobs, the initial unemployment rate and the ethnic proportions (given by the model parameters initial-unemployment-rate and eth-proportions). For the experiments reported in this paper, the latter have been derived by linear regression from the case study data (Waldinger \& Lichter 2003, Tables A2, A4-A8), which specify the working population in $\%$ for the different industry sectors and ethnicities for the years 1970, 1980 and 1990. The model initialisation uses the values for 1960 shown in Table 2.

[Insert Table 2 about here]

The model world is resized to easily fit the number of agents before creating all employers and workers. The employed proportion of native workers is then hired by the employers making sure that Whites and Blacks are evenly spread over all firms, i.e. that each firm ends up with a similar ratio of Whites to Blacks.

$\sim 18 \sim$ 
Immigration, social networks and the emergence of segmentation

Finally, the ethnically separated social networks are initialised. Each worker forms some links with other workers of the same ethnicity in their vicinity. The number of links is determined by taking a sample from a random exponential distribution with mean given by the model parameter mean-initial-links, and then taking the minimum of this sample and the number of co-ethnics in the Moore neighbourhood of depth 5 of the respective agent. Links are undirected, therefore having one agent form a link with another agent means that both of them gain a 'friend'. Agents may thus gain additional links to their own initially formed links, resulting in a highly skewed degree distribution as is typical for social networks.

\subsection{Calibration}

We calibrated the model with a small labour market setup of 11 employers, offering a total of 2103 jobs, and the ethnicity proportions given above. Birth rates per ethnicity were taken from official statistics for 1990 (Livingston \& Cohn, 2012), using the values for native-born Blacks, foreign-born Hispanics and foreign-born Asians (8.62\%, 13.69\%, and $7.85 \%$, respectively). The value for native-born Whites had to be adapted so that the overall population dynamics of the model correlates with the trajectories of the numbers of unskilled workers per ethnic group as reported in the case study data (see section 4.4 above).

In the absence of empirical data on actual, historical immigration rates into the case study area, immigration of the non-native ethnic groups ('Latino' and 'Asian') in the model is driven by the success of co-ethnics already in the labour market. The lower the unemployment rate, the higher the immigration rate. However, once employment falls 
below a certain level ( $90 \%$ during calibration), immigration will cease until that level is again exceeded. This is subject to a 2-tick information delay (see, e.g. Stalker, 2000).

Calibration resulted in the birth rate for Whites set to $0.5 \%$ (this acknowledges the fact that the White model population is mostly moving out of the low-skilled labour market over the modelled period of 30 years). We also derived fixed immigration rates for both non-native ethnicities for each year, with the initial vacancy proportion set to $10 \%$.

These rates have been applied in subsequent simulation runs with a larger labour market of 100 employers and a total of 5000 jobs, to make comparison between different model settings easier and take the influence of varying immigration rates on model results out of the equation.

\section{$5 \quad$ Results and findings}

Our concern in this paper was to model Waldinger \& Lichter's How the Other Half Works with particular reference to the impact of homophilic social networks on processes of labour market segmentation in low-skill jobs where formal entry requirements are negligible (Bauder, 2006; Piore, 1979; Sassen, 1996). Therefore, we focus on i) the conditions in which ethnic segmentation occurred in the model, and ii) the relative impact of homophilic social networks under conditions of two forms of 'conservative' discrimination by employers; that is, employers seeking to match their workforce with an imagined customer-base - in this case, the total population of the model (Waldinger \& Lichter, 2003: 131) - or to maintain the ethnic 'balance' of the firm, in order not to disrupt the delicate bonds of influence, obligations and implicit contracts within the organisation (ibid: 83).

$\sim 20 \sim$ 
Immigration, social networks and the emergence of segmentation

All model scenarios use the same configuration of firms (100 employers with a total of 5000 jobs); all experiments were run for 30 years (1560 ticks). Results depicted in this section are usually averaged over ten simulation runs per scenario to account for probabilistic variance, if not stated otherwise.

\subsection{Segmentation measures}

To measure relative segmentation we apply a multigroup segregation indicator that is able to take several ethnic groups into account instead of measuring segregation between just two population groups, as is standard in segregation measures. Reardon \& Firebaugh (2002) developed and evaluated six different multigroup segregation indices and suggest the information theory index $H$ as the best. It is based on viewing segregation as 'a function of the disproportionality in group proportions across organizational units', which suits our application case. The $\mathrm{H}$ index can be formalised for multi-ethnic labour market segmentation as follows; where $p_{m}=$ proportion of ethnicity $m$ in the population, $M=$ number of different ethnicities, $p_{j m}=$ proportion of ethnicity $m$ in firm $j, J=$ number of firms, $t_{j}=$ number of workers in firm $j$, and $T=$ total population:

$H=\frac{1}{E} \sum_{m=1}^{M} p_{m} \sum_{j=1}^{J} \frac{t_{j}}{T} r_{j m} \ln r_{j m}$

with Theil's Entropy index $E=\sum_{m=1}^{M} p_{m} \ln \left(1 / p_{m}\right)$ applied as the disproportionality function. The ratio $r_{j m}=p_{j m} / p_{m}$ expresses the extent to which ethnicity $m$ is disproportionately represented in firm $j: r_{j m}<1$ indicates $m$ is underrepresented; $r_{j m}>1$ indicates $m$ is overrepresented in firm $j$. 
The $\mathrm{H}$ index can be interpreted as 'one minus the ratio of the average within-unit population diversity to the diversity of the total population' (Reardon \& Firebaugh 2002:42). The closer the average diversity within firms matches the diversity of the total population, the nearer this ratio gets to 1 , therefore the closer the $\mathrm{H}$ index gets to 0 (no segmentation). The more the diversity within firms diverges from the diversity of the total population, the higher the $\mathrm{H}$ index (higher segmentation). This allows us to easily compare two different simulated scenarios and establish which one leads to relatively higher segmentation.

In addition, we apply indicators we derived from the case study itself. After successfully completing model calibration we undertook several simulation experiments with the small setup of the labour market (11 employers, 2103 jobs) before scaling up to the large labour market of 100 firms. This allowed us to investigate how segmentation develops within individual firms over time. We found that - as expected and in accordance with Waldinger \& Lichter's work - some organisations can become dominated by one of the initially minority immigrant groups (see Figure 1, employer 3, 4 or 6); they basically 'take over' the firm. It is also possible for organisations dominated by a native ethnic group to 'lock out' immigrant groups (see Figure 1, employer 7). This is also a feature described in Waldinger \& Lichter's work, whereby certain organisations (particularly those with more bureaucratic hiring regulations) tend to remain dominated by native workers.

[Insert Figure 1 about here.] 
Immigration, social networks and the emergence of segmentation

To be used as segmentation indicators, we define a lock-out to occur when the proportion of native workers in a firm is greater than $80 \%$; similarly, a take-over has happened when the proportion of immigrant workers in a firm is greater than $80 \%$. To avoid overshadowing of the indicators by the population dynamics in this low-skilled labour market, where a White majority is slowly displaced by Latino immigrants, whereas the proportion of Blacks remains steady at around 10\% of the population (see data in section 4.4), we decided to measure the number of lock-outs and take-overs not at the end but after 20 years of simulation (tick 1040).

\subsection{Impact of social networks on segmentation}

In Waldinger \& Lichter's theorisation, social networks are of central importance to the development of ethnically segmented labour markets - they allow for information about job vacancies in niche areas to flow rapidly within ethnically homogenous networks where members are already employed within that niche, meaning certain groups could react more quickly than others to opportunities. Employers, meanwhile, could utilise these networks as a cost-effective way to gain employees with pre-existing obligations, not only to their employer, but also their co-workers and fellow network members. However, the degree to which such networks impact on the extent and rate of segmentation is difficult to specify without a control where such networks do not exist. Whilst this is not possible in 'real world' research, one use of agent-based models is running just such a 'null' hypothesis and compare it to a 'standard' model.

In the standard model described in section 4, employment processes are influenced by both homophilic social networks (workers receive information about vacancies, employers receive recommendations for applicants from existing employees) and $\sim 23 \sim$ 
spatial effects (unemployed workers without useful ties apply at the nearest firm with vacancies, new agents try to 'settle down' next to other agents of their own ethnic group). To test the impact of these, we compared this model with model variants without one or both of these influences. In the so-called 'null' model, agents do not have social networks and space is basically reduced to one location so that all distances between firms and workers are identical. The third model variant lies in between: Agents have social networks but space is not modelled.

As can be seen from Figure 2, the impact of the social network on labour market segmentation is substantial. While there is no segmentation in the null model, both the standard model and its variant without space show significant segregation levels. The $H$ index for the standard model stabilises at a value of 0.4 , about $30 \%$ higher than that for the model without space but social networks.

\section{[Insert Figure 2 here]}

This implies that, whilst they are not the sole cause of segmentation in the model (the geographic proximity of agents to particular firms and each other also plays a part), ethnically homogenous social networks substantially increase the overall level of ethnic segmentation within the model. Furthermore, in certain scenarios, such segmentation can become extreme, particularly for groups with a small (initial) cohort. Whilst system variation is to be expected, it is clear that introducing ethnically homogenous social networks increases the propensity for smaller groups to become highly concentrated within certain sectors of the labour market. In the case shown in Figure 3, this is true for both natives and immigrants as the two smaller ethnic groups (native 'Blacks' and 
Immigration, social networks and the emergence of segmentation

immigrant 'Asians') are excluded from more than $75 \%$ of firms at the end of the simulation with the standard model.

[Insert Figure 3 about here]

\subsection{Effects of 'conservative' discrimination by employers}

Discrimination by employers has long been flagged up as a key component in the ethnic segmentation of labour markets. Alongside the notion of immigrants as a 'reserve army' of labour, social and cultural distinctions mark certain workers as more suitable for certain kinds of jobs (Bauder, 2006; Bourdieu, 2007; Wills et al., 2010). However, what form this discrimination takes has the potential to radically change the way ethnic segmentation in the labour market occurs. In this paper we test two forms of 'conservative' discrimination; in the first part of the experiment we assume that employers wish to conserve the current make-up of their workplace in order to preserve the functional order of the organisation. Only where the maintenance of the current ethnic balance of the workforce is impossible will the employer look further afield. We term this internally conservative discrimination (ICD).

In modelling terms, the ethnic proportions are translated into probabilities of selecting a particular ethnicity to filter the pool of potential candidates. This means that if an organisation employs 75\% 'White', 10\% 'Black and 15\% 'Latino', and there are one 'White' applicant and two 'Black' applicants for a job, there is a 75\% chance that the 'White' applicant is chosen. If there are several candidates of the pre-selected ethnicity, the one with the most recommendations will gain the job as before. In case there are none, recruitment follows the 'standard' referral hiring process. Thus any candidates 
from ethnic groups not yet present in a firm will only get a role in this organisation if no other candidates apply.

In the second part of the experiment, we assume that employers seek to build a workforce that reflects their 'customer base' (Waldinger \& Lichter, 2003: 199). We describe this as externally conservative discrimination (ECD). Whilst this may be a more relevant form of discrimination in roles that involve a direct engagement with the public, such as restaurants and service jobs in hotels and hospitals, it provides a subtly different form of discrimination.

Here, we modelled this process as employers having a bias towards hiring workers who would help their workforce reflect the overall population diversity of the model. Therefore, if we take the scenario described previously, where an organisation is composed of $75 \%$ 'White', 10\% 'Black' and 15\% 'Latino', and add the caveat that the overall population is $60 \%$ 'White', $10 \%$ 'Black', 25\% 'Latino' and 5\% 'Asian', then the probability of each of the four ethnic groups being selected to choose a candidate from, notwithstanding social network recommendations, is $0.6,0.1,0.25$ and 0.05 , respectively. If there is no candidate of the pre-selected ethnicity, normal referral hiring resumes.

We implemented both forms of discrimination in the 'standard' model and also the 'null' model, in order to be able to gauge the effect of homophilic social networks in these scenarios. Figure 4 shows results for both model variants and the two forms of discrimination. It also includes the previous scenario, the standard referral hiring (leftmost bars in Fig. 4), for comparison. 
Immigration, social networks and the emergence of segmentation

[Insert Figure 4 about here]

ICD leads to a noticeable increase in ethnic segmentation, mostly to the detriment of the immigrants groups. The average number of lock-outs with the standard model rises from 32 with normal referral hiring to 38.6 with ICD, an increase of $20 \%$, while the average number of take-overs decreases by about the same proportion from 24.4 to 19.2 (see Figure 4, left). The high number of lock-outs shows that immigrants are restricted to a relatively small segment of the labour market. It is interesting to note that social networks do not seem to have much of a mitigating effect in this form of discrimination: the average level of lock-outs for the ICD scenario with the 'null' model is about the same as with the 'standard' model (35 versus 38.6); only the average number of take-overs is noticeably lower (14.3 versus 24.4). Since our simulated labour market starts from a situation where only natives are employed in any of the firms, it is hard for immigrants to 'get a foot in the door' when employers try to maintain the existing ethnic composition of their workforce. Only the existence of an initial surplus in vacancies makes it possible for immigrants to gain employment. But once a successful toehold is formed, their chances increase and social network processes will tend to reinforce that nascent advantage, as is evident in the higher number of take-overs in the standard model compared to the null variant.

With the second form of discrimination, when no social networks exist, there is negligible ethnic segmentation (Figure 4, right). This is unsurprising as the ECD scenario means that employers actively seek to match their workforce to the overall population. However, despite this tendency, ethnic segmentation does occur when social networks are present, though this is far less pronounced than in the ICD scenarios, $\sim 27 \sim$ 
and entails a reduction from non-discriminatory scenarios (the average number of lockouts is about halved, whereas take-overs are nearly completely eliminated compared to normal referral hiring, see Figure 4, left).

Again, therefore, social networks have the impact of buffering migrant groups against the negative effects of discrimination, whilst increasing the propensity for such groups (especially if they are small) to become 'ghettoised' in the labour market. However, of perhaps greater significance, are the notably different impacts of internally- and externally-conservative discrimination regimes. Whilst both initially have negative impacts for immigrant incorporation into the labour market, once migrants begin to gain a foothold in organisations, ICD effectively acts to make certain organisations easier targets than others for migrant groups which already have co-ethnics employed there. ECD, on the other hand, effectively acts as a form of positive discrimination, constantly counter-acting the tendency of social networks to focus on 'easy' targets (i.e. where the concentration of co-ethnics are high) and forcing them to wait for breakthroughs where they are currently under-represented. This is very effective in reducing labour-market segmentation.

\section{Discussion and conclusions}

In this article we have used an agent-based modelling approach to investigate the impact of social networks and employer discrimination on the development of ethnic segmentation in low-skill labour markets driven by referral hiring. Our research has illustrated that ethnically homogenous social networks significantly increase ethnic segmentation in the labour market. Indeed, this impact outweighs that of the 
Immigration, social networks and the emergence of segmentation

'conservative' discrimination procedures tested. Furthermore, such homophilic networks also enhance the ability of immigrant groups to gain a foothold in the labour market, particularly under conditions of discrimination. These findings broadly support the results of an earlier agent-based model of referral hiring and ethnic segmentation (Abdou \& Gilbert, 2009), as well as Waldinger \& Lichter's (2003) own analysis. However, we have also shown that the form of discrimination has a powerful effect on ethnic segmentation in the labour market. This raises a number of questions and implies that it would be highly beneficial for migration scholars and economic geographers to turn their attention to the initiation, establishment and, crucially, the evolution of migrant social networks and their relationship to the development of ethnic niches in the labour market. Additionally, we must remain aware that the form of discrimination can substantially change its population-level impacts. Following the findings of this study, as well as key debates in economic geography and migration studies, we may ask whether the development of ethnically homogenous social networks are the only successful response to the challenges of gaining employment in low-skill labour markets.

Furthermore, this model does not contend with how such networks evolve once a niche has been formed - do they become a barrier to further integration as some theorists have suggested (Lancee, 2012; Ooka \& Wellman, 2006), or do they mutate and dissipate as migrant groups learn the language and cultural norms of the host, as human capital theory would imply (Duvander, 2001)?

Whilst there is no novelty in stressing the point that ethnic social networks have a significant impact on the labour market success and segmentation of immigrant communities, what we have achieved here is to gauge the relative extent of the impact $\sim 29 \sim$ 
of such networks on labour market segmentation and success, both for different initial cohorts of migrants, and also as compared to 'conservative' discrimination. This has been done with reference to a very specific (though relatively common) type of labour market - one that is driven by referral hiring and with few barriers to employment. The relative impact of ethnic social networks, forms of discrimination and group size may alter substantially where the mechanics of the labour market are different. For example, where entry requirements are higher and require either country-specific qualifications, a level of competence in the host language, or both, the relative strength of impact of these factors is likely to change (see, e.g. Tarvid, 2016).

However, we have illustrated that migration scholars and economic geographers can meaningfully model non-linear emergent processes in a way that feeds back into key debates in the disciplines and allows us to combine the reproducibility and generality of quantitative approaches with a commitment to the nuance and locality inherent in qualitative methods. It is our hope that scholars with a specialisation in either approach will find something here to discuss and extend in future research.

\section{$7 \quad$ Acknowledgments}

The research for this project was made possible by funding through the Environmental and Physical Sciences Research Council (EPSRC) funded "Social Complexity of Immigration and Diversity" (SCID) project (EPSRC project EP/H02171X/1). We acknowledge the comments and assistance given to us in developing this model from the participants in various workshops on the Labour Markets and Ethnic Segmentation (LAMEST) model at the University of Manchester, and from those who attended the 
Immigration, social networks and the emergence of segmentation

'Beyond Schelling and Axelrod' workshop at Manchester Metropolitan University in 2017. Last but not least we would like to thank the anonymous reviewers whose comments helped us to improve this paper. Any errors or omissions contained in the article, however, are entirely the fault of the authors.

\section{Author Information}

Ruth Meyer is a Research Fellow at the Centre for Policy Modelling (http://cfpm.org), a research-only unit of the MMU Business School, which focuses on complexity science and social simulation. Her research interests include agent-based simulation, spatial modelling and simulation methodologies in general. She has over fifteen years of experience modelling complex social systems during her PhD at Hamburg University and subsequently at the CPM. With Bruce Edmonds she co-edited the handbook on "Simulating Social Complexity" for Springer, which is now in its second edition. Email: r.meyer@mmu.ac.uk

Huw Vasey is a Research Associate in the Multilingual Manchester team in the School of Arts, Languages and Cultures, and a member of the Manchester Migration Lab, both at the University of Manchester. He is a social anthropologist and human geographer whose work has focused on international migration and processes of adaptation and change post-migration, including labour market integration, inter-ethnic marriage and community diversity, and language use and needs in super-diverse cities. Information on previous work is available at https://manchester.academia.edu/HuwVasey. Email: huw.vasey@manchester.ac.uk 


\section{References}

Abdou, M. \& N. Gilbert. 2009. 'Modelling the emergence and dynamics of social and workplace segregation'. Mind \& Society 8(2): 173-191.

Bauder, Harald. 2006. Labor Movement: How Migration Regulates Labor Markets. Oxford: Oxford University Press.

Bourdieu, Pierre. 2007. The Social Structures of the Economy. London: Polity Press.

Boyd, M. \& J. Nowak. 2012. 'Social networks and international migration' in M. Martinello J. Rath, eds. An Introduction to International Migration Studies. Amsterdam: Amsterdam University Press; pp. 79 - 105.

Calvo-Armengol, A. \& M.O. Jackson. 2004. 'The effects of social networks on employment and inequality'. American Economic Review 44: 426-484.

$\&$ .2007. 'Networks in labor markets: wage and employment dynamics and inequality'. Journal of Economic Theory 132: 27-46.

Chattoe-Brown, Edmund. 2013. 'Why Sociology should use agent based modelling'. Social Research Online 18(3) 3. www.socresonline.org.uk/18/3/3.html

Duvander, Ann-Zofie. 2001. 'Do country-specific skills lead to improved labor market positions? An analysis of unemployment and labor market returns to education among immigrants in Sweden'. Work and Occupations 28(2): 210-233 
Immigration, social networks and the emergence of segmentation

Edmonds, Bruce. 2013. 'Complexity and context-dependency'. Foundations of Science 18(4): 745-755.

Gemkow, Simon \& Michael Neugart. 2011. 'Referral hiring, endogenous social networks, and inequality: an agent-based analysis'. Journal of Evolutionary Economics 21: 703-719.

Geyer, Robert \& Samir Rihani. 2010. Complexity and Public Policy: A New Approach to $21^{\text {st }}$ Century Politics, Policy and Society. London: Routledge.

Gilbert, Nigel \& Klaus G. Troitzsch. 2005. Simulation for the Social Scientist. Second Edition. Maidenhead: Open University Press.

Herzog, H.W. Jr, A.M. Schlottmann \& T.P. Boehm. 1993. 'Migration as a spatial job-search: a survey of empirical evidence'. Regional Studies 27(4): 327-340.

Krauth, B.V. 2004. 'A dynamic model of job networking and social influences on employment'. Journal of Economic Dynamics Control 28: 1185-1204.

Lancee, Bran. 2012. Immigrant Performance in the Labour Market: Bonding and Bridging Social Capital. Amsterdam: Amsterdam University Press.

Livingston, Gretchen, and Cohn, D’Vera. 2012. U.S. Birth Rate Falls to a Record Low; Decline Is Greatest Among Immigrants. Section 3: Race, Ethnicity and National Origin. Pew Research Center, 2012. http://www.pewsocialtrends.org/2012/11/29/raceethnicity-and-national-origin/ 
Massey, Douglas S., Joaquin Arango, Graeme Hugo, Ali Kouaouci, Adela Pellegrino, and J. Edward Taylor. 1993. 'Theories of international migration: A review and appraisal'. Population and Development Review 19 (3):431-466.

McDowell, Linda, Adina Batnitzky \& Sarah Dyer. 2009. 'Precarious work and economic migration: emerging immigrant divisions of labour in Greater London's service sector'. International Journal of Urban and Regional Research 33(1): 3-25.

Meyer, Ruth. 2018. 'LaMEStModel (Version 1.0.0)'. CoMSES Computational Model Library. Retrieved from: https://www.comses.net/codebases/3490002b-24af-467a-87f38f24723ba0f4/releases/1.0.0/

Mol, Annemarie, and John Law. 2002. 'Complexities: An Introduction'. In Complexities: Social Studies of Knowledge Practices, J. Law and A. Mol, eds. London: Duke University Press; pp. 1-22.

Ooka, Emi \& Barry Wellman. 2006. 'Does social capital pay off more within or between ethnic groups? Analysing job searches in five Toronto ethnic groups' in E. Fong, ed. Inside the Mosaic. Toronto: University of Toronto Press; pp. 199-226.

Papastergiadis, Nikos. 2004. The Turbulance of Migration: Globalization, Deterritorialization and Hybridity. Cambridge: Polity Press.

Piore, Michael. 1979. Birds of Passage. Migrant Labor and Industrial Society. Cambridge: Cambridge University Press.

Reardon, Sean F., \& Firebaugh, Glenn. 2002. 'Measures of Multigroup Segregation'. Sociological Methodology 32(1): 33-67.

$\sim 34 \sim$ 
Immigration, social networks and the emergence of segmentation

Sassen, Saskia. 1996. 'New employment regimes in cities: the impact on immigrant workers'. New Community 22(4): 579-594.

Sawyer, Robert. 2005. Social Emergence: Societies as Complex Systems. Cambridge: Cambridge University Press.

Sorensen, Aage B. 1998. 'Theoretical mechanisms and the empirical study of social processes' in P. Hedstrom \& R. Swedberg, eds. Social Mechanisms. Cambridge: Cambridge University Press; pp. 238-266.

Stalker, Peter. 2000. Workers Without Frontiers: The Impact of Globalization on International Migration. London: Lynne Rienner.

Tarvid, A. 2016. 'Using Agent-Based Modelling in Studying Labour-Education Market System' in A. Tarvid Agent-Based Modelling of Social Networks in Labour-Education Market System. Cham: Springer, pp. 39-72.

Tassier, T \& F. Menczer. 2008. 'Social network structure, segmentation and equality in a labour market with referral hiring'. Journal of Economic Behaviour and Organisation 66: 514-528.

Waldinger, Roger, and Michael I. Lichter. 2003. How the Other Half Works: Immigration and the Social Organization of Labor. London: University of California Press.

Wilensky, Uri. 1999. NetLogo. Center for Connected Learning and Computer-Based Modeling, Northwestern University. Evanston, IL. http://ccl.northwestern.edu/netlogo/ 
Wills, Jane, Kavita Datta, Yara Evans, Joanna Herbert, Jon May \& Cathy McIlwaine. 2010. Global Cities at Work: New Migrant Divisions of Labour. London: Pluto Press. 
Immigration, social networks and the emergence of segmentation

Table 1: Characteristics of firms derived from the case study data.

\begin{tabular}{|c|c|c|c|c|c|c|}
\hline \multirow[t]{2}{*}{ Parameters } & \multicolumn{6}{|c|}{ Industry sectors } \\
\hline & Printing & $\begin{array}{l}\text { Furniture } \\
\text { manufacturing }\end{array}$ & Restaurants & Hotels & $\begin{array}{l}\text { Department } \\
\text { stores }\end{array}$ & Hospitals \\
\hline $\begin{array}{l}\text { Proportion of } \\
\text { firms }\end{array}$ & $14 \%$ & $6 \%$ & $73 \%$ & $5 \%$ & $1 \%$ & $1 \%$ \\
\hline $\begin{array}{l}\text { Number of } \\
\text { jobs (mean) }\end{array}$ & 20 & 32 & 16 & 39 & 209 & 850 \\
\hline $\begin{array}{l}\text { Number of } \\
\text { jobs } \\
\text { (standard } \\
\text { deviation) }\end{array}$ & 23 & 41 & 181 & 141 & 89 & 250 \\
\hline $\begin{array}{l}\text { Annual } \\
\text { turnover rate }\end{array}$ & $10 \%$ & $17 \%$ & $25 \%{ }^{2}$ & $6 \%$ & $22 \%$ & $4 \%$ \\
\hline
\end{tabular}


Table 2: Proportions of ethnic groups in the population over time derived from the case study data.

\begin{tabular}{|lllll|}
\hline Ethnicity & 1960 & 1970 & 1980 & 1990 \\
\hline White & $87.96 \%$ & $70.70 \%$ & $52.01 \%$ & $36.19 \%$ \\
Black & $9.63 \%$ & $9.50 \%$ & $11.57 \%$ & $9.23 \%$ \\
Latino & & & & \\
Asian/Other & $2.39 \%$ & $14.94 \%$ & $27.60 \%$ & $40.04 \%$ \\
& $0.02 \%$ & $4.86 \%$ & $8.82 \%$ & $14.54 \%$ \\
\hline
\end{tabular}


Immigration, social networks and the emergence of segmentation

Figure 1: A typical run of the standard model with small labour market setup, showing time series of the ethnic proportions of workers of the 11 different employers. Immigrant groups are displayed in grey (green/orange in the colour version), while natives are black (darkgrey/red).
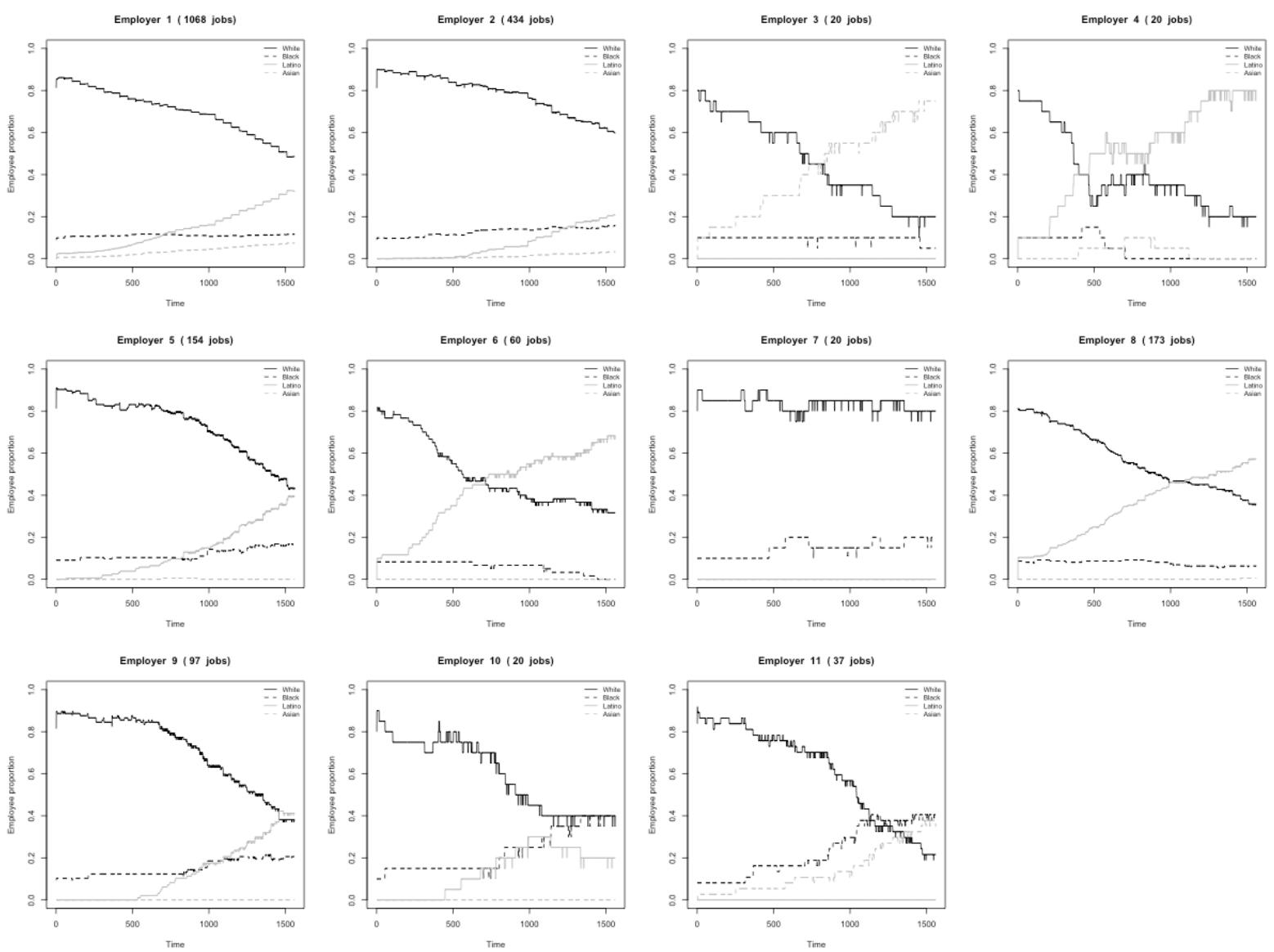
Figure 2: Segmentation with referral hiring, measured by the H index, for three different scenarios.

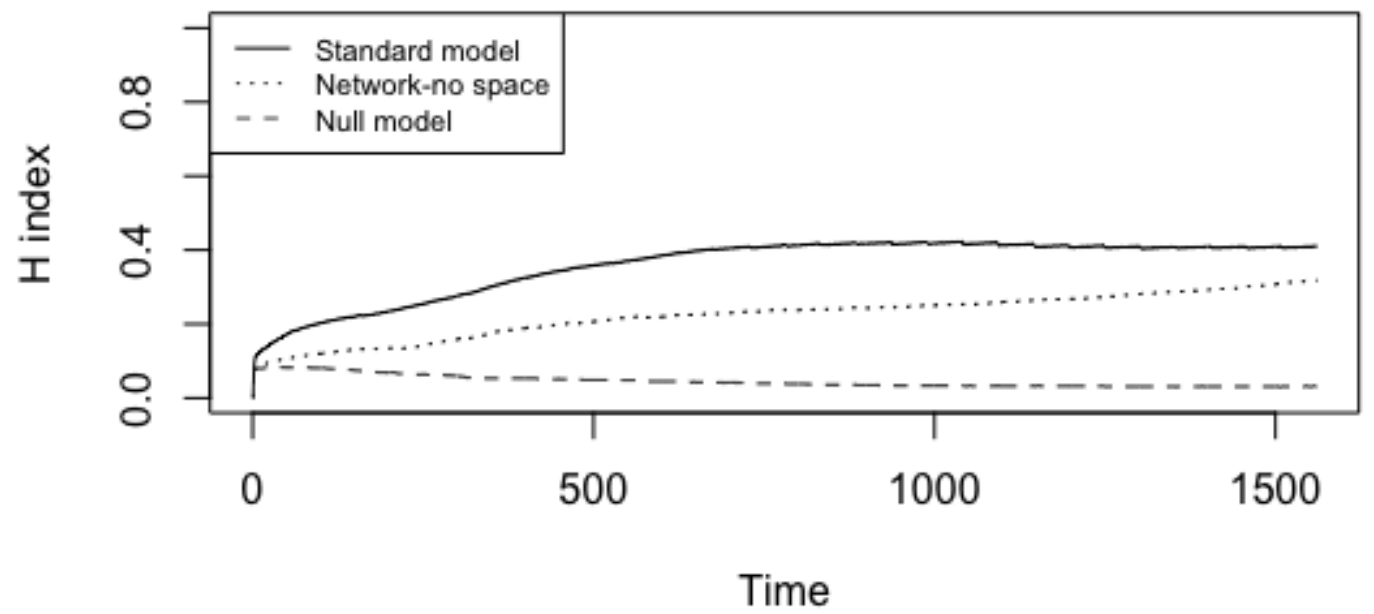

$\sim 40 \sim$ 
Immigration, social networks and the emergence of segmentation

Figure 3: Number of firms for each ethnicity where workers of that ethnic group are not present at the end of the simulation; taken from a typical run of the standard model.

\section{Exclusions from firms}

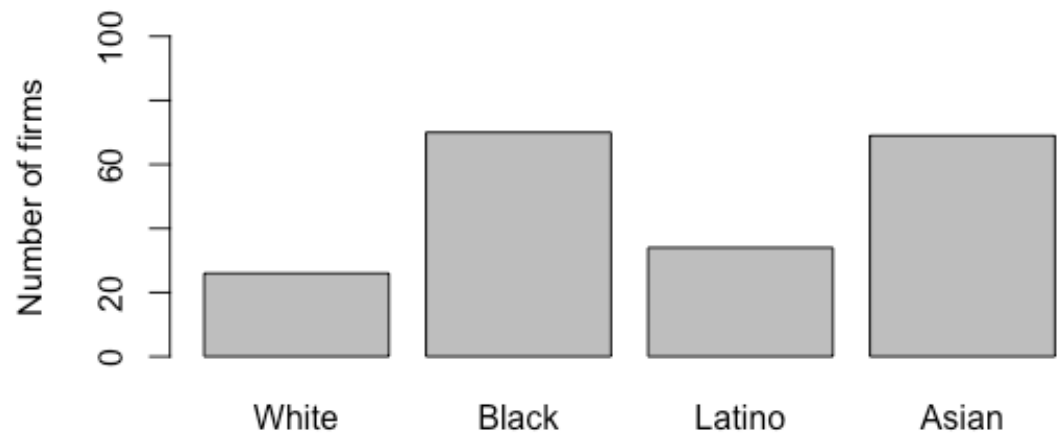


Figure 4: Effects of discrimination in the 'standard' model (left) and the 'null' model (right).
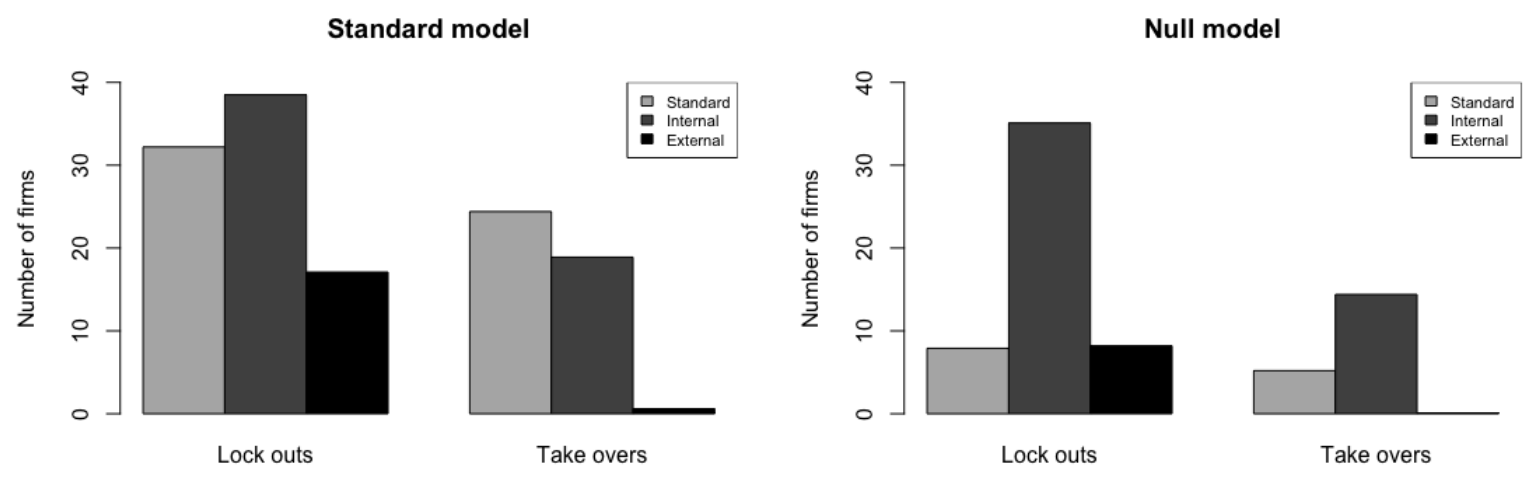
Immigration, social networks and the emergence of segmentation

\section{Endnotes}

${ }^{1}$ In case of several applicants with the highest number of recommendations, a random one of these is chosen. Agents without recommendations therefore only have a chance of employment if none of the existing employees have any unemployed friends applying for a job at the same time.

2 The annual turnover rate for restaurants is missing in the case study data. We have assumed a value slightly higher than those for the other industries to account for the fact that the turnover rate in the restaurant sector is notoriously high.

3 The case study data specifies numbers for native-born and foreign-born Latinos separately. For the sake of simplicity (and to avoid negative numbers for 1960), these have been combined for use in the model. 